\title{
Health Promotion Behavior among Patients with Type 2 Diabetes Mellitus - A Cross Sectional Survey
}

\author{
Mariamma V George ${ }^{1}$, Dr. Jayarani Premkumar ${ }^{2}$ \\ ${ }^{1}$ Principal, Shri Vinoba Bhave College of Nursing, Silvassa, UT of DNH \\ ${ }^{2}$ Former Nursing Superintendent, Christian Medical College, Vellore, Tamilnadu
}

\begin{abstract}
A Cross sectional survey was conducted to assess the health promotion behavior of patients with type 2 diabetes mellitus. The study was conducted in selected government hospitals of Udupi district, Karnataka. Health promotion behavior (HPB) was measured by a questionnaire on Health promotion behavior for type 2 diabetes developed by the researcher. Data was collected after obtaining informed consent. HPB was categorized as poor, average and good. Majority (63\%) of the patients had average HPB in dietary adherence, whereas most (43\%) of them had good HPB in exercise and majority (66\%) of them had good adherence to drug regimen. Majority (61\%) had average adherence to overall HPB.
\end{abstract}

Keywords: Health Promotion Behavior, Type 2 Diabetes Mellitus

\section{Introduction}

In 2008, an estimated 347 million people in the world had diabetes and the prevalence is growing, particularly in low and middle income countries. India had 69.2 million people living with diabetes as per the 2015 data. Of these, it remained undiagnosed in more than 36 million people. ${ }^{[1]}$

Controlling blood sugar levels is the primary goal of diabetes management. The management of diabetes is complex and lifelong. Adherence to dietary restrictions, regular exercise and compliance to drug therapy are key to the management of diabetes. Dietary restrictions play a major role in the management of diabetes. It is important to ensure that glycemic levels are kept within boundaries to prevent fluctuations in blood sugar. Sedentary life style is a major risk factor for the development of diabetes. Exercise helps in taking the sugar in to the muscles and lowers the blood sugar. It is believed that exercise can reduce insulin resistance. Adherence to medications is important. Taking food and drugs on time regularly helps maintain blood sugar levels. Proper follow up is important for early identification and prevention of complications of diabetes.

\section{Statement of the Problem}

A study to assess the health promotion behavior among patients with type 2 diabetes mellitus in selected government hospitals of Udupi, Karnataka.

\section{Objectives}

The objective of the study was to assess the health promotion behavior of patients with type 2 diabetes mellitus.

\section{Materials and Methods}

A cross sectional study was conducted among 100 diabetic patients from selected government hospitals of Udupi,

Karnataka. Health promotion behavior was assessed by a practice questionnaire developed by the researcher. Health promotion behavior included three sub categories. Dietary restrictions included 11 items, exercise five items and adherence to medication three items. Subjects rated their Health promotion behavior on a 5-point Likert scale on how well they practiced HPB (i.e. from "never" (scored as 0) to "always" (scored as 4). HPB was categorized as poor, average and good. Data was collected after obtaining informed consent. Data was analyzed using descriptive statistics.

\section{Results}

Table 1: Distribution of subjects based on demographic and morbidity variables

\begin{tabular}{|l|c|c|}
\hline \multirow{2}{*}{ Demographic variables } & \multicolumn{2}{c|}{ Frequency/Percentage } \\
\cline { 2 - 3 } & $f$ & $\%$ \\
\hline Age in years & & \\
\hline $1.35-40$ & 3 & 3 \\
\hline $2.41-50$ & 24 & 24 \\
\hline $3.51-60$ & 27 & 27 \\
\hline $4.61-70$ & 42 & 42 \\
\hline 5. $>$ 70 & 4 & 4 \\
\hline Gender & & \\
\hline 1. Male & 48 & 48 \\
\hline 2. Female & 52 & 52 \\
\hline Marital status & & \\
\hline 1.Married & 88 & 88 \\
\hline 2.Widow/ Widower & 12 & 12 \\
\hline Religion & & \\
\hline 1. Hindu & 84 & 84 \\
\hline 2. Muslim & 8 & 8 \\
\hline 3. Christian & 8 & 8 \\
\hline Educational status & & \\
\hline 1. Primary & 2 & 2 \\
\hline 2. Secondary & 40 & 40 \\
\hline 3. High School & 20 & 20 \\
\hline 4. Pre University & 30 & 30 \\
\hline 5. Graduate & 3 & 3 \\
\hline 6. Post graduate & 5 & 5 \\
\hline
\end{tabular}

\section{Volume 6 Issue 12, December 2017}


International Journal of Science and Research (IJSR)

ISSN (Online): 2319-7064

Index Copernicus Value (2016): 79.57 | Impact Factor (2015): 6.391

\begin{tabular}{|c|c|c|}
\hline \multicolumn{3}{|l|}{ Occupational status } \\
\hline 1. Unemployed & 19 & 19 \\
\hline 2. Unskilled & 41 & 41 \\
\hline 3. Semiskilled & 29 & 29 \\
\hline 4. Skilled & 3 & 3 \\
\hline 5. Shop/ farm owner & 1 & 1 \\
\hline 6. Semi professional & 7 & 7 \\
\hline \multicolumn{3}{|l|}{ Monthly income in rupees } \\
\hline $1 .>5001$ & 21 & 21 \\
\hline $2.4001-5000$ & 15 & 15 \\
\hline 3. 3001-4000 & 25 & 25 \\
\hline 4. $2001-3000$ & 26 & 26 \\
\hline 5. $<2000$ & 13 & 13 \\
\hline \multicolumn{3}{|l|}{ Duration of diabetes in years } \\
\hline 1. Less than 5 years & 54 & 54 \\
\hline 2. 5-10 years & 37 & 37 \\
\hline 3. $11-15$ years & 6 & 6 \\
\hline 4. Above 15 years & 3 & 3 \\
\hline \multicolumn{3}{|l|}{ Treatment } \\
\hline Oral hypoglycemic agents & 98 & 98 \\
\hline $\begin{array}{l}\text { Oral hypoglycemic agents and } \\
\text { Insulin }\end{array}$ & 2 & 2 \\
\hline \multicolumn{3}{|l|}{ Body Mass Index } \\
\hline Normal: $18.5-24.99$ & 44 & 44 \\
\hline Overweight: $25-29.99$ & 46 & 46 \\
\hline Obese : above 30 & 10 & 10 \\
\hline
\end{tabular}

Table 3: Mean, Median and Standard Deviation of HPB

\begin{tabular}{|c|c|c|c|c|c|}
\hline Domains of HPB & $\begin{array}{c}\text { Min } \\
\text { Score }\end{array}$ & $\begin{array}{c}\text { Max } \\
\text { Score }\end{array}$ & Mean & SD & Median \\
\hline HPB: Diet & 24 & 44 & 32.94 & 4.19 & 32.00 \\
\hline HPB: Exercise & 4 & 20 & 13.29 & 3.23 & 14.00 \\
\hline HPB: Medication & 6 & 12 & 10.00 & 1.64 & 10.00 \\
\hline HPB. Total & 38 & 69 & 56.23 & 6.13 & 57.00 \\
\hline
\end{tabular}

The data presented in table no: 2 shows that mean HPB with regard to Medication was $10 \pm 1.645$ and the mean score of Total HPB was $56.23 \pm 6.13$

\section{Discussion}

The present study results showed that HPB on dietary adherence was good in $27 \%$ and average in $63 \%$, whereas HPB in exercise was poor in $19 \%$, average in $38 \%$ and good in $43 \%$. HPB related to medications was poor in $2 \%$, average in $34 \%$ and good in $66 \%$ and overall HPB was average in $38 \%$ and good in $61 \%$.

A study from a tertiary health care setting in Karnataka also reported healthy eating plan on a daily basis by $45.9 \%$, daily exercises for $30 \mathrm{~min}$ by $43.4 \%$ and adherence to medication among $60.5 \%$ of the participants. ${ }^{[2]}$

The data presented in table 1 shows that most (42\%) of the subjects belonged to the age group of 61 to 70 years and 27 of them were between 51 to 60 years. Most (52\%) of them were male by gender and $88 \%$ of the subjects were married and living with their spouse. Majority (84\%) of them were Hindu by religion. Most (40) of them were with secondary education, and $41 \%$ of them were unskilled workers and $54 \%$ of them were with duration of illness less than 5 year's duration. Majority (98\%) of the subjects were on oral hypoglycemic agents and most (46\%) of them were overweight with body mass index between 25-29.9

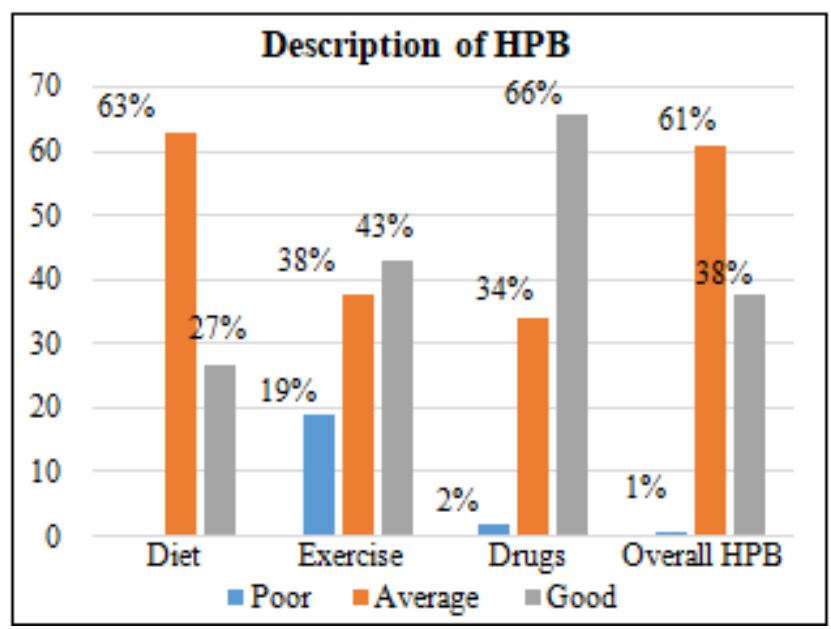

Chart 1: Domain wise description of health Promotion behavior among subjects

The data presented in the above chart on subcategories of HPB reveals that majority $63 \%$ of the subjects had average HPB in dietary adherence, whereas most $(43 \%)$ of them had good HPB in exercise and majority $(66 \%)$ of them had good adherence to drug regimen. Majority (61\%) had average adherence to overall HPB.

Similar results were also reported in a study conducted in Kashmir in which $23.26 \%$ of them had moderate and $76.74 \%$ of them had high level of dietary adherence. Level of physical activity in low, moderate and high level were $15.70 \%, 52.90 \%$ and $31.40 \%$ respectively. Medication adherence in low, moderate and high level were $8.13 \%$, $70.94 \%$ and $20.93 \%$ respectively. ${ }^{[3]}$

A community based survey in urban southern India on selfcare activities of diabetics also showed good dietary behavior in $29 \%$, good exercise behavior in $19.5 \%$ and drug adherence in $79.8 \%{ }^{[4]}$

Similar findings were reported in a study conducted in Karnataka in which compliance to treatment was found to be $82.1 \%$. Sixty percent reported doing regular exercise whereas almost $92 \%$ of respondents were following diet control advices ${ }^{[5]}$

\section{Recommendations}

1) Behavioral intervention programmes for diabetic patients that promotes adherence to Health promotion behavior

2) Individualized plan for management of diabetic patients to enhance the efficacy of interventions.

3) Family oriented intervention packages to enhance family support to facilitate adherence to HPB

\section{Conclusion}

Adherence to medication was good in most of the subjects whereas adherence to dietary restrictions was only average in majority of the subjects. Health professionals must develop behavioral intervention programmes for better adherence to dietary restrictions and to promote health promotion behavior among diabetes patients in order to

\section{Volume 6 Issue 12, December 2017}




\section{International Journal of Science and Research (IJSR) \\ ISSN (Online): 2319-7064}

Index Copernicus Value (2016): 79.57 | Impact Factor (2015): 6.391

prevent the complications and to improve the quality of life with diabetes.

\section{References}

[1] WHO.World health day 2016. Diabetes. www. searo. who.int/india/mediacentre /events/2016/ en

[2] Rajasekharan D, Kulkarni V, Unnikrishnan B, Self-Care Activities Among Patients with Diabetes Attending a Tertiary Care Hospital in Mangalore Karnataka, India. Annals of Medical and Health Science Research. 2015 Jan-Feb; 5(1): 59-64

[3] Nisa U, Shafi H. Psychological factors and self-care behaviors as correlates of Medication Adherence among Insulin-taking Type 2 Diabetes patients. IOSR Journal of Humanities and Social Science (IOSR-JHSS) Volume 21, Issue11, Ver. 6 (Nov. 2016) PP 01-06.

[4] Gopichandran V, Lyndon S, Angel MK, et al. Diabetes self-care activities: a community-based survey in urban southern India. National Medical Journal of India. 2012Jan-Feb;25(1):14. www.ncbi.nlm.nih. gov /pubmed /22680314

[5] Khymdeit E, Rao PA, Narayanan P, Mayya S. Social support influencing diabetes self-management behaviors: A cross-sectional study in Udupi Taluk. Indian Journal of Health Sciences. 2016; 9:153-7.

Volume 6 Issue 12, December 2017

www.ijsr.net 